\title{
Smartphone-assisted minimally invasive neurosurgery
}

\author{
Mauricio Mandel, MD, ${ }^{1,2}$ Carlo Emanuel Petito, MD, ${ }^{1,2}$ Rafael Tutihashi, MD, PhD, ${ }^{1,2}$ \\ Wellingson Paiva, MD, PhD, ${ }^{1}$ Suzana Abramovicz Mandel, MD, ${ }^{2}$ \\ Fernando Campos Gomes Pinto, MD, PhD, ${ }^{1}$ Almir Ferreira de Andrade, MD, PhD, ${ }^{1}$ \\ Manoel Jacobsen Teixeira, MD, PhD, ${ }^{1}$ and Eberval Gadelha Figueiredo, MD, PhD1
}

\begin{abstract}
'Division of Neurosurgery, Hospital das Clínicas of University of São Paulo Medical School; and ${ }^{2}$ Hospital Israelita Albert Einstein, São Paulo, Brazil
\end{abstract}

OBJECTIVE Advances in video and fiber optics since the 1990s have led to the development of several commercially available high-definition neuroendoscopes. This technological improvement, however, has been surpassed by the smartphone revolution. With the increasing integration of smartphone technology into medical care, the introduction of these high-quality computerized communication devices with built-in digital cameras offers new possibilities in neuroendoscopy. The aim of this study was to investigate the usefulness of smartphone-endoscope integration in performing different types of minimally invasive neurosurgery.

METHODS The authors present a new surgical tool that integrates a smartphone with an endoscope by use of a specially designed adapter, thus eliminating the need for the video system customarily used for endoscopy. The authors used this novel combined system to perform minimally invasive surgery on patients with various neuropathological disorders, including cavernomas, cerebral aneurysms, hydrocephalus, subdural hematomas, contusional hematomas, and spontaneous intracerebral hematomas.

RESULTS The new endoscopic system featuring smartphone-endoscope integration was used by the authors in the minimally invasive surgical treatment of 42 patients. All procedures were successfully performed, and no complications related to the use of the new method were observed. The quality of the images obtained with the smartphone was high enough to provide adequate information to the neurosurgeons, as smartphone cameras can record images in high definition or $4 \mathrm{~K}$ resolution. Moreover, because the smartphone screen moves along with the endoscope, surgical mobility was enhanced with the use of this method, facilitating more intuitive use. In fact, this increased mobility was identified as the greatest benefit of the use of the smartphone-endoscope system compared with the use of the neuroendoscope with the standard video set.

CONCLUSIONS Minimally invasive approaches are the new frontier in neurosurgery, and technological innovation and integration are crucial to ongoing progress in the application of these techniques. The use of smartphones with endoscopes is a safe and efficient new method of performing endoscope-assisted neurosurgery that may increase surgeon mobility and reduce equipment costs.

https://thejns.org/doi/abs/10.3171/2017.6.JNS1712

KEY WORDS brain aneurysm; epilepsy; intracerebral hematoma; subdural hematoma; third ventriculostomy; neuroendoscopy; smartphone; surgical technique

$\mathrm{C}$ OMPUTER technology is increasingly being integrated into medical care. ${ }^{16,18,19}$ Use of handheld computproviders and throughout the general population. ${ }^{10,28,31,34}$ In particular, over the last decade there have been rapid developments in smartphones. These mobile phones can perform many of the functions of the most sophisticated computer devices, particularly with regard to speed, storage capacity, optical resolution, and camera functionality, ${ }^{17}$ and their compact size makes them useful in settings that may be inaccessible to larger computers and cameras. At the same time, the role of state-of-the-art technology in neurosurgical procedures has become essential as surgeons strive to achieve optimal results using less invasive meth- 
TABLE 1. Demographic characteristics and outcomes for all patients

\begin{tabular}{|c|c|c|c|}
\hline Factor & Vascular Neurosurgery & Intraventricular Neuroendoscopy & Emergency Neurosurgery \\
\hline No. of patients & 24 & 6 & 12 \\
\hline Sex & $6 \mathrm{M} / 18 \mathrm{~F}$ & $4 \mathrm{M} / 2 \mathrm{~F}$ & $10 \mathrm{M} / 2 \mathrm{~F}$ \\
\hline Mean age in yrs & 58 & 6 & 45 \\
\hline Diagnosis & $\begin{array}{l}\text { MTC } 3(\text { CD 1.8-2.5 cm) } \\
\text { PCoA An } 13(\text { AD 3-15 mm) } \\
\text { ACoA An } 6 \text { (AD 3-10 mm) } \\
\text { AChA An } 2 \text { (AD 4-7 mm) }\end{array}$ & $\begin{array}{l}\text { Aqueductal stenosis } 2 \\
\text { Idiopathic hydrocephalus } 2 \\
\text { Aqueductal low-grade glioma } 2\end{array}$ & $\begin{array}{l}\text { SDH } 3 \\
\text { Contusional hematoma } 4 \\
\text { Spontaneous intracerebral hematoma } 5\end{array}$ \\
\hline Side & Rt $11 /$ lt 13 & - & Rt 9/lt 3 \\
\hline Surgical procedure & $\begin{array}{l}\text { Nanopterional } 14 \\
\text { Transpalpebral } 10\end{array}$ & $\begin{array}{l}\text { 3rd ventriculostomy } 6 \\
\text { Intraventricular biopsy } 2\end{array}$ & $\begin{array}{l}\text { Frontal trepanation } 7 \\
\text { Temporal trepanation } 1 \\
\text { Parietal trepanation } 3\end{array}$ \\
\hline $\begin{array}{r}\text { General surgical } \\
\text { complications }\end{array}$ & $\begin{array}{l}1 \text { ischemic event (radiological evidence of } \\
\text { a small perforator stroke at the genu of } \\
\text { the internal capsule, asymptomatic) } \\
\text { No residual neck on control angiography }\end{array}$ & $\begin{array}{l}1 \text { pt received a ventriculoperito- } \\
\text { neal shunt }\end{array}$ & Detailed in Table 2 \\
\hline Clinical complications & None & None & 2 pts w/ ventilator-associated pneumonia \\
\hline
\end{tabular}

$\mathrm{ACh} A=$ anterior choroidal artery; $\mathrm{ACOA}=$ anterior communicating artery; $\mathrm{AD}=$ aneurysm diameter $\mathrm{An}=$ aneurysm; $\mathrm{CD}=$ cavernoma diameter; $\mathrm{MTC}=$ mesial temporal cavernoma; $\mathrm{PCOA}=$ posterior communicating artery; $\mathrm{pt}=$ patient.

No complications associated with the integrated smartphone-endoscope approach were observed. Details regarding the emergency neurosurgery cases are presented in Table 2.

ods. ${ }^{11}$ Accordingly, high-resolution endoscopes are already being routinely used for neurosurgery worldwide. ${ }^{1,2,7}$ As yet, however, the integration of high-resolution endoscopes and handheld computers (including smartphones) remains a novel concept.

Although some currently available neuroendoscopes can record still images and video through the use of camera systems attached to the endoscopic tube, these instruments are typically more expensive than smartphones. Standard video systems included with endoscopes are larger than mobile phones, may not be widely available, and may lack the telecommunication and data collection capabilities unique to a mobile phone. Smartphones are widely available, relatively inexpensive, and are more portable than a standard video stack system with a camera, light source, and camera control unit. In the present study, we used a neuroendoscope modified to be coupled with an iPhone (Apple Inc.) by the addition of a specially designed adaptor. To our knowledge, this is the first such study in the medical literature and may represent a low-cost and more intuitive solution for minimally invasive procedures in neurosurgery.

\section{Methods}

Between October 2010 and July 2015, a total of 42 patients with various neuropathological disorders (cavernomas, anterior circulation brain aneurysms, hydrocephalus, subdural hematomas [SDHs], and contusional and spontaneous intracerebral hematomas) underwent minimally invasive surgery performed with the use of a smartphone-endoscope set at the Hospital das Clínicas of the University of São Paulo Medical School. Patients with a Glasgow Coma Scale (GCS) score of 3, coagulopathy, or treatment with antiplatelet or anticoagulant therapy were excluded from the study. The patient population consisted of 20 male and 22 female patients, with a mean age of 40.7 years (range 1-68 years) (Table 1). The clinical courses, radiological findings, and outcomes in these patients were evaluated; however, because observational data for only a small population were collected, no inferential statistical analysis was performed.

All patients underwent minimally invasive surgical procedures. CT images were processed using the DICOM software OsiriX preoperatively, as described previously. ${ }^{19}$ An exclusively endoscopic technique or a combined endoscopic-microscopic technique, both of which were performed with the neuroendoscopic device coupled to a smartphone, was chosen according to the neurosurgeon's preference. A rigid rod lens endoscope (Karl Storz) was used in all patients. Rigid scopes with diameters of 2.7 or $4.0 \mathrm{~mm}$ and angles of $0^{\circ}, 30^{\circ}$, or $45^{\circ}$ were used. For more recent cases, specially designed $2.7-\mathrm{mm}$ rigid scopes (11 and $18 \mathrm{~cm}$ long) with either $0^{\circ}$ or $30^{\circ}$ lenses (Karl Storz) were used. The scope was held by the primary surgeon in all cases.

In all cases, a ClearScope adapter (Clearwater Clinical) or a Scope Adaptor (ClearSight) was used to attach the neuroendoscope to the smartphone (Fig. 1). Although the smartphones we used in the procedures were the iPhone 4, iPhone 5, and iPhone 6 models, almost all currently available smartphones can be used in the same manner. Care was always taken to start the procedure with the device fully charged, providing a battery life of approximately 12 hours. Although not required in this study, charging the device during a procedure would be possible by placing a plastic cover over the charging cable.

A plastic cover was used to isolate the iPhone from the 


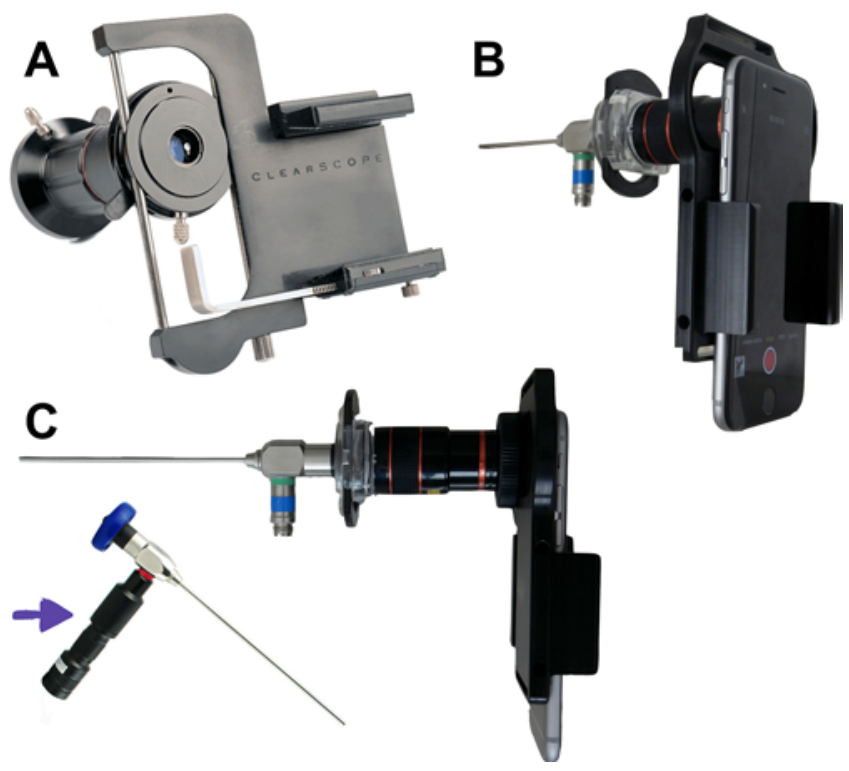

FIG. 1. Photographs showing use of the iPhone and neuroendoscope. A: The ClearScope Smart Phone Adaptor allows the connection of a mobile device to almost any endoscope. The unit secures the smartphone to a rigid platform that connects to an adjustable telescope over the camera lens. B: The Scope Adaptor is an older version with the same functions. C: The authors used a range of endoscopes with different lengths $(4,6,9$, and $12 \mathrm{~cm})$, thicknesses $(2.7-4 \mathrm{~mm}$ in diameter), and angles $\left(0^{\circ}, 30^{\circ}\right.$, and $\left.45^{\circ}\right)$. Illumination was provided by using a xenon light source, which passes the light through a standard optical fiber, or a portable light source (blue arrow). sterile surgical field. Illumination was provided by a xenon light source, which passes the light through a standard optical fiber, or by a portable light source, which requires no cable, as shown in Fig. 1. The primary surgeon used the smartphone to visualize the surgical field while performing the neuroendoscopic procedure. However, a standard video system was always available in case the surgeon did not feel confident about images obtained through the smartphone. The images on the smartphone screen could also be displayed on a larger TV screen via $\mathrm{Wi}-\mathrm{Fi}$, where they could be viewed by the assistant surgeon if this was necessary.

\section{Intraventricular Neuroendoscopy}

Six patients with a mean age of 6 years underwent intraventricular procedures. Four of these patients were children younger than 4 years, including 2 children diagnosed with idiopathic congenital hydrocephalus and 2 children with hydrocephalus secondary to congenital aqueduct stenosis. Images from a representative case, which illustrate the surgeon's use of the smartphone-endoscope set and the surgical field, as seen on the smartphone screen, are shown in Fig. 2.

\section{Vascular Neurosurgery}

Twenty-four patients (6 male and 18 female patients, mean age 58 years) underwent cerebral aneurysm clipping or arteriovenous malformation (cavernoma) resection. The smartphone-endoscope set was used as an adjunct in
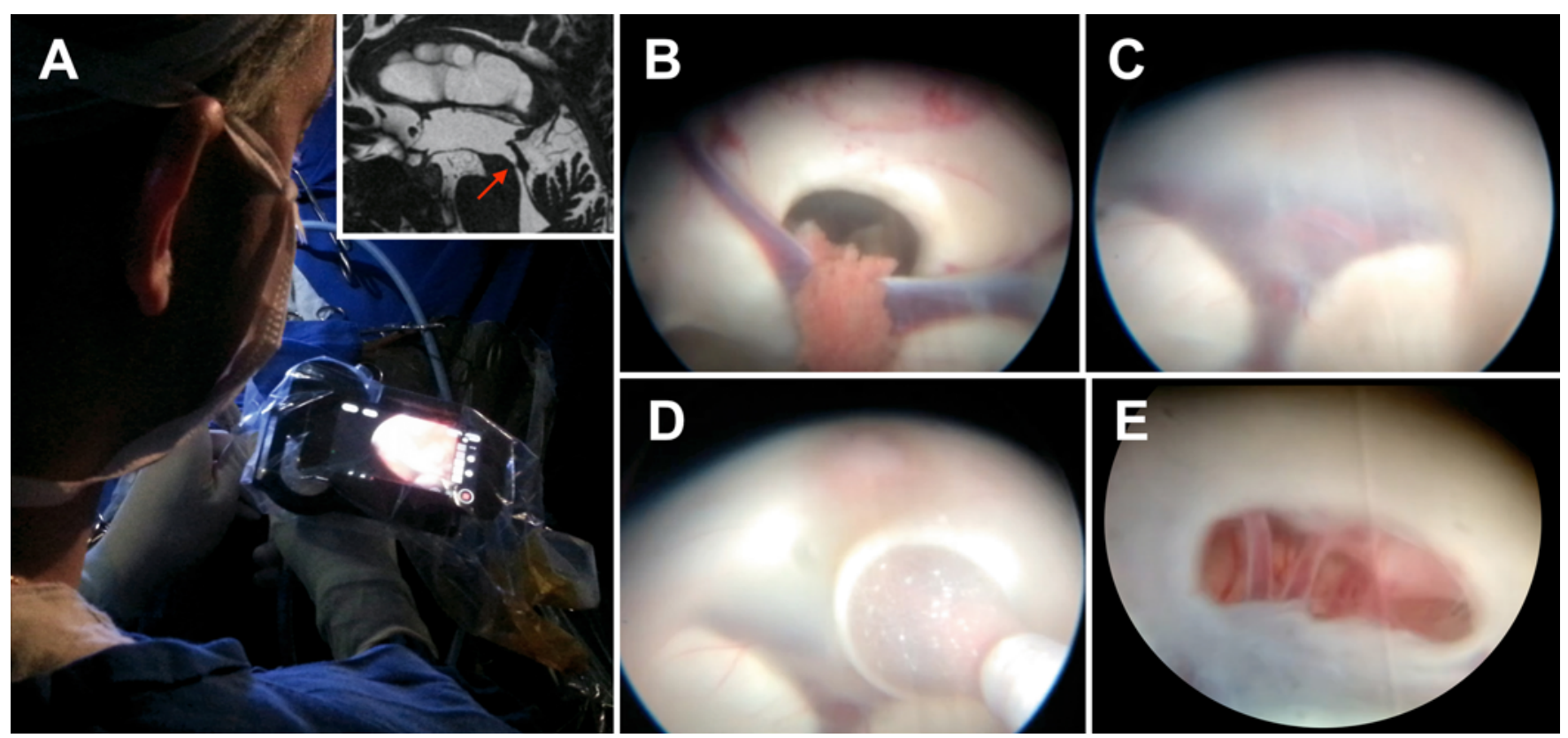

FIG. 2. Intraventricular neuroendoscopy with the use of a smartphone for aqueductal stenosis in a 6-month-old male infant, in whom an abnormal progressive increase in head circumference had developed since birth. A: Photograph obtained during surgery with an MR image of the brain demonstrating hydrocephalus due to idiopathic aqueductal stenosis (red arrow in inset). The endoscopic procedure is performed in a standard manner except for the addition of the iPhone attached to the endoscope, which provided a viewing screen that allowed the surgeon's gaze to remain on the surgical field. B-E: The iPhone provided the surgeon with endoscopic views of the foramen of Monro (B), an ideal spot for fenestration (C and D), and the final aspect of the field (E). The $4 \mathrm{~K}$ camera resolution allows adequate visualization of perforating arteries, thus allowing the surgeon to avoid causing inadvertent injuries. After this surgery the patient progressed well with no need for additional procedures. 

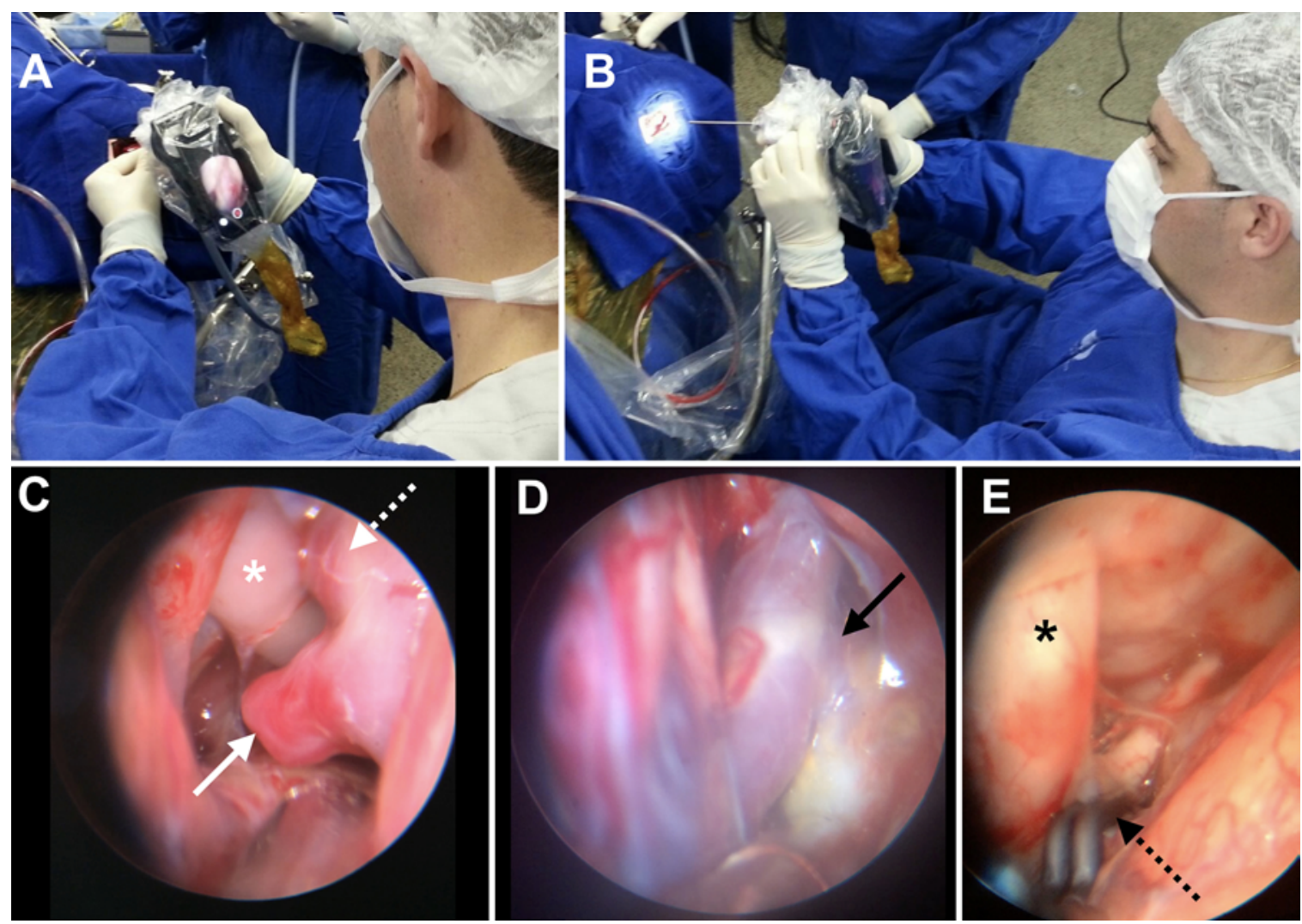

FIG. 3. Vascular neurosurgery for incidental brain aneurysms. A and B: Photographs showing the surgeon using the new smartphone-endoscope system to inspect aneurysms before and after clipping. C-E: Views of the surgical field available to the primary surgeon on the iPhone screen. In vascular case $1(\mathrm{C})$, the solid white arrow points to the anterior choroidal artery aneurysm, and the dashed white arrow points to the posterior communicating artery aneurysm. The third nerve (white asterisk) is also shown. In vascular case 2 (D), the neck of the posterior communicating artery aneurysm is clearly displayed (black arrow). In vascular case 3 (E), the aneurysm clip (dashed black arrow) rests above the left optic nerve (black asterisk); no residual aneurysm is apparent.

the microsurgical treatment of clipping aneurysms in 21 patients with 22 aneurysms, all of which were located in the anterior circulation. A keyhole approach was adopted in all of these patients. The iPhone attached to the neuroendoscope was used to observe anatomical features of the aneurysm neck and perforating arteries and to verify the optimal clipping position, as shown for representative cases 1-3 in Fig. 3. For cases involving cavernomas, the iPhone screen was used to inspect the surgical cavity to identify any vascular malformation remnants and bleeding spots during hemostasis.

\section{Emergency Neurosurgery}

Four patients admitted to the emergency department were diagnosed with contusional hematomas and 5 were diagnosed with spontaneous intracerebral hematomas (Table 2). Both types of hematomas were treated using a neuroendoscopic technique that has already been described by several authors, ${ }^{12,13,19,25,27,32}$ with the addition of the smartphone for visualization of the surgical field. Three patients with SDH underwent endoscopic excision through a parietal tangential burr hole. The rationale for the method involved the endoscopic drainage of acute SDH through a burr hole in the parietal region. Images from the representative case (Fig. 4) show that the small display provided the surgeon with adequate visualization and enhanced mobility.

\section{Results}

Demographic and outcome data on the patients and information on lesion locations are provided in detail in Tables 1 and 2. Use of the smartphone enabled the surgeon to employ a more dynamic and intuitive approach to resection because of enhanced mobility while keeping the surgical field in view. Image quality was considered equal to that of a standard HD video set. The plastic sterile drape over the screen did not interfere with the quality of the image. None of the surgeons found it necessary to substitute the new system with the former one. Even though the smartphone had a small display, the surgeons rarely needed to view the larger screen to which the image was transmitted via Wi-Fi.

\section{Intraventricular Neuroendoscopy}

All of the surgeries involving intraventricular neuroendoscopy were uneventful. All intraventricular procedures were performed in a standard fashion through an endoscopic trocar with working channels. Because the smartphone allowed the surgeon to visualize the surgical field 
TABLE 2. Demographic characteristics and outcomes in patients requiring emergency neurosurgery

\begin{tabular}{|c|c|c|c|c|c|c|c|c|c|c|c|c|c|}
\hline Case No. & $\begin{array}{l}\text { Age } \\
\text { (yrs) }\end{array}$ & TA & $\begin{array}{l}\text { GCS } \\
\text { Score }\end{array}$ & Location & Side & $\begin{array}{l}\text { Lesion } \\
\text { Vol } \\
(\mathrm{ml})\end{array}$ & $\begin{array}{l}\text { Associated } \\
\text { Lesion }\end{array}$ & $\begin{array}{l}\text { Incision } \\
\text { Length } \\
\text { (cm) }\end{array}$ & $\begin{array}{l}\text { Craniotomy } \\
\text { Diam }(\mathrm{cm})\end{array}$ & $\begin{array}{l}\text { LOS } \\
\text { Neuro } \\
\text { (days) }\end{array}$ & $\begin{array}{c}\text { LOS } \\
\text { Hospital } \\
\text { (days) }\end{array}$ & $\begin{array}{l}\text { GOS } \\
\text { Score }\end{array}$ & $\begin{array}{l}\text { Gross Neuro } \\
\text { Exam }\end{array}$ \\
\hline \multicolumn{14}{|c|}{ Acute \& subacute SDH } \\
\hline 1 & 37 & $2 \mathrm{hrs}$ & 14 & FTP & Rt & 32 & TSAH & 3 & 2 & 3 & 4 & 5 & No deficits \\
\hline 2 & 38 & $1 \mathrm{hrs}$ & 14 & FTP & Rt & 37 & - & 3 & 2 & 4 & 5 & 5 & No deficits \\
\hline 3 & 47 & 2 days & 10 & FTP & Rt & 43 & - & 3 & 2 & 2 & 4 & 5 & No deficits \\
\hline \multicolumn{14}{|c|}{ Contusional hematoma } \\
\hline 4 & 44 & $4 \mathrm{hrs}$ & 10 & $\mathrm{~F}$ & $\mathrm{Lt}$ & 35 & TSAH & 3 & 1.5 & 5 & 5 & 5 & Mild aphasia \\
\hline 5 & 28 & $1 \mathrm{hr}$ & 12 & $\mathrm{~F}$ & Rt & 34 & $\mathrm{SDH}$ & 3 & 1.5 & 10 & 21 & 4 & No deficits \\
\hline 6 & 30 & 40 mins & 6 & $\mathrm{~F}$ & Rt & 33 & EDH & 2 & 2 & 12 & 12 & 4 & No deficits \\
\hline 7 & 41 & 30 mins & 6 & $\mathrm{~T}$ & Lt & 32 & LSDH & 2.5 & 2 & 7 & 7 & 4 & No deficits \\
\hline \multicolumn{14}{|c|}{$\begin{array}{l}\text { Spontaneous intrace- } \\
\text { rebral hematoma }\end{array}$} \\
\hline 8 & 65 & $2 \mathrm{hrs}$ & 13 & $B G$ & Rt & 35 & - & 2 & 2 & 10 & 21 & 4 & Lt hem (G4) \\
\hline 9 & 55 & $1 \mathrm{hr}$ & 6 & BG & Rt & 60 & - & 3 & 2 & 15 & 15 & 3 & Lt hem (G4) \\
\hline 10 & 58 & 30 mins & 10 & $B G$ & Rt & 40 & - & 2.5 & 2 & 12 & 15 & 3 & Lt hem (G3) \\
\hline 11 & 53 & $2 \mathrm{hrs}$ & 13 & PF & $\mathrm{Lt}$ & 13 & - & 2.5 & 1.5 & 7 & 7 & 5 & No deficits \\
\hline 12 & 59 & $1 \mathrm{hr}$ & 14 & PF & Rt & 15 & - & 2.5 & 1.5 & 9 & 9 & 5 & No deficits \\
\hline
\end{tabular}

without the need for cables, freedom of movement was enhanced. We found that the screen sizes of the iPhones 4, 5, and 6 did not impair the handling of instruments through working channels. There were no postoperative complications related to this method. To ensure good visualization for the assistant surgeon, it was essential to display the smartphone screen on a larger screen connected by Wi-Fi. However, for the primary surgeon who held the endoscope, the fluidity of intraventricular navigation appeared to be enhanced compared with the standard method.

\section{Vascular Neurosurgery}

All vascular surgeries were uneventful. During these procedures, the smartphone-endoscope set was used only for visualization. Since microscopes with indocyanine green were not available at our institution, it was important to use the visual display provided by the smartphone to confirm proper clipping of the aneurysms. The use of a smartphone connected to the neuroendoscope also enabled better maneuverability, because the neuroendoscope and display followed the same movement. Another interesting observation was that as the screen moved along with the image, the surgeon's 3D perception of the surgical field was enhanced. Hence, the surgeon felt confident in safely navigating through the surgical cavity. No damage to important structures, such as brain parenchyma, cranial nerves, or arteries, was observed. Moreover, the image quality was exceptional. The small screen was not a problem as it was positioned well ahead of the surgeon. None of the surgeons using the smartphones found it necessary to view the larger display to resolve any unclear portion.

\section{Emergency Neurosurgery}

The general characteristics surrounding cases requiring emergency neurosurgery are summarized in Table 2 . The average volume of spontaneous and contusional hematomas was $33 \mathrm{ml}$. These hematomas were resected using the same method as that used for spontaneous hematomas. All hematomas were resected satisfactorily. In these cases, the chief surgeon held the smartphone-endoscope set in one hand and the surgical tools (aspirator or bipolar coagulator) in the other hand. The surgeon did not find it difficult to maneuver the endoscope with just one hand because the whole set weighed only $305 \mathrm{~g}$. None of the surgeons experienced any difficulty in maneuvering instruments close to the larger screen of the iPhone 6; however, we believe that screens larger than that found on the iPhone 6 could cause difficulty in maneuvering.

Three patients diagnosed with SDH (2 patients with acute SDH and 1 patient with subacute SDH) underwent surgery. These patients all had lesions that extended over the entire brain convexity, with volumes ranging from 32 to $43 \mathrm{ml}$. Three-dimensional planning, using OsiriX software, was used to determine the location of a tangential burr hole, such that a rigid endoscope and aspirator/ bipolar coagulator tool could be introduced over the entire surface of the brain. The intraoperative view of the smartphone-endoscope set was satisfactory and enabled safe and complete resection of the hematoma. By using a 


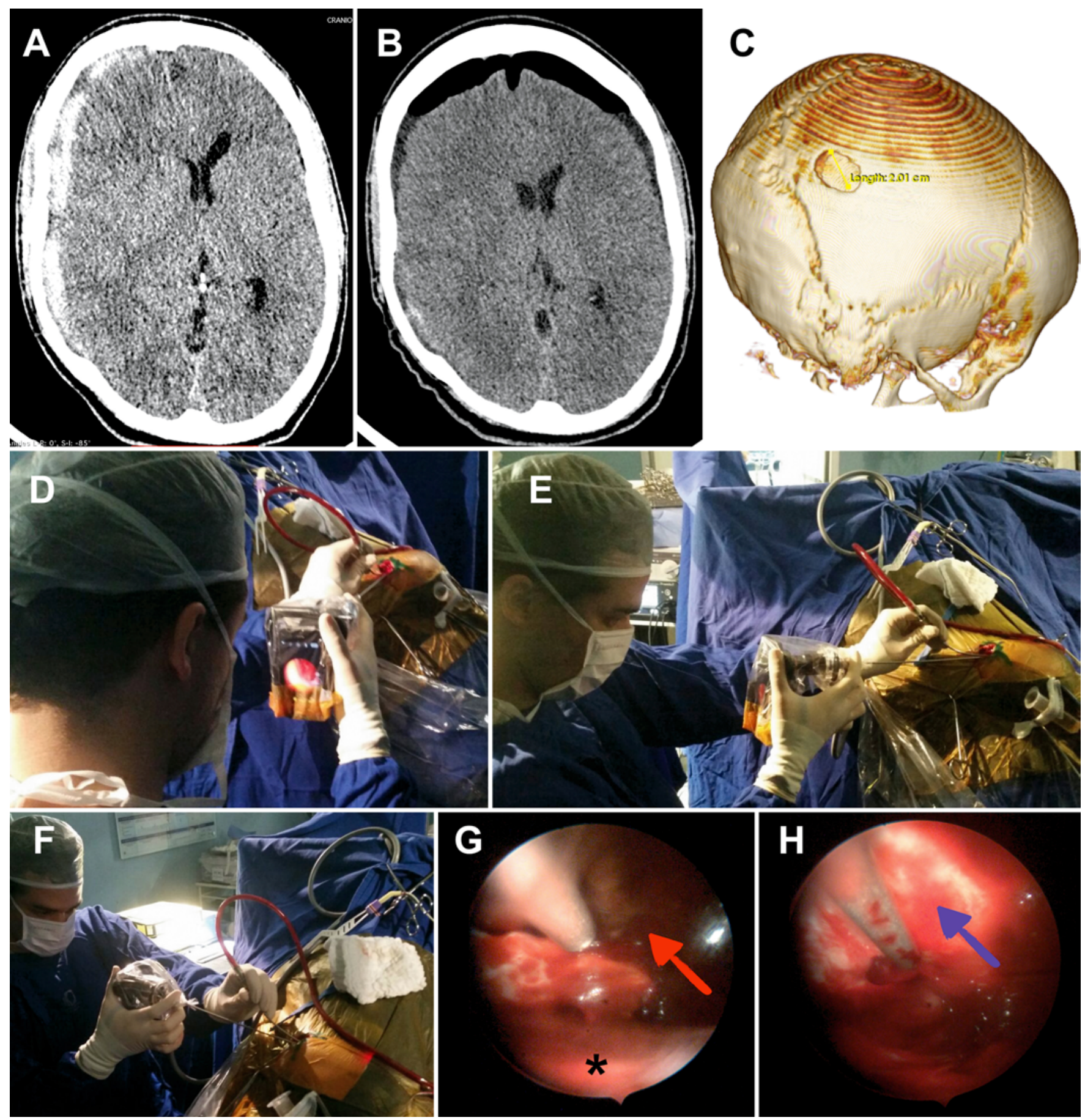

FIG. 4. Emergency neurosurgery for an SDH. A 47-year-old male patient was brought to the emergency department by relatives. Two days earlier he had experienced a 2-meter fall, but feeling well afterward he did not immediately seek medical attention. On admission, the patient presented with a GCS score of 14 and left hemiparesis with muscle strength grade 4. A-C: Preoperative CT scans and CT reconstruction. The scans show a subacute SDH extending over the entire convexity of the right brain. In patients harboring SDHs without brain swelling, it is possible to perform a complete endoscopic resection. Essential to this procedure is an adequate entry point (C) adjacent to the hematoma. D-F: Photographs obtained during surgery. During endoscopic resection, it is possible to insert an endoscope with an aspirator or a bipolar coagulator tool. The small display on the smartphone provided the surgeon with adequate visualization and enhanced mobility because the smartphone screen moves along with the endoscope. G and H: Endoscopic images displayed on the smartphone screen show the SDH (red arrow) being removed by the aspirator and the uncovering of the dura mater (blue arrow) and brain (asterisk). The patient experienced an excellent recovery with reversal of his preoperative deficits. He was discharged from the hospital 4 days after hospital admission. 
4-mm, $0^{\circ}$ or $30^{\circ}$ endoscope, the surgeons could easily perform hematoma suctioning, hemostasis, and examination of the subdural space to locate contusional bleeding spots and bridging veins. All patients recovered completely from their symptoms and were discharged in 2 days.

\section{Discussion}

Thus far in the early 21st century there has been an unanticipated major transformation in the field of communication modalities, which has led to the widespread use of mobile communication devices. The popularity of smart devices in medical teaching is increasing, and several applications (apps) and adaptors are currently available. ${ }^{17}$ Hence, given the increasing quality of the cameras and screen resolution of these devices, integration of an iPhone or other smartphone with a neuroendoscope appears inevitable. However, one unexpected advantage of using this integrated system is the improved experience offered by the placement of a smartphone screen in front of an endoscope, which makes use of the endoscope more intuitive and enhances $3 \mathrm{D}$ perception.

There are many advantages of using smart devices in neurosurgery. Compared with traditional video stacks, smartphones are relatively inexpensive and portable, and they do not require an external power supply. The presence of high-quality camera optics enables real-time image acquisition, storage, manipulation, and transmission via a spectrum of wireless technologies, including Bluetooth, near-field communication, Wi-Fi, and $3 \mathrm{G}$ or $4 \mathrm{G}$. Images can also be transmitted to larger screens for teaching purposes or for intraoperative assessment in cases of shared surgery; moreover, these images can be streamed via thirdparty applications to other smart devices or websites.

The smartphone-endoscope device used in this study was easy to set up and offered the ability to manipulate the image by using the smartphone camera functions in real time. The lens system used in this study can be used to connect any smartphone to an endoscope by removing the lens adaptor and incorporating this into a hard-back plastic phone cover.

\section{Intraventricular Neuroendoscopy}

During the initial neuroendoscopic procedures of the 20th century, it was difficult to look through an endoscope. 5 The advent of use of a camera along with the endoscope helped improve the visualization of intraventricular procedures and enabled the assistant surgeon to play an active role during surgery. However, surgeons needed to look over to the screen on one side and maneuver the endoscope on the other side. Although this technique becomes easier after much practice, it will never be considered natural behavior by the brain. The introduction of the smartphone realigns the surgeon's view directly to the endoscope, while providing exceptional image quality with $4 \mathrm{~K}$ resolution. At the same time, it enables Wi-Fi transmission of the image to a larger display in the operating room, thus ensuring that the assistant surgeon has a role to play.

All cases of intraventricular surgery in this study were uneventful; however, as the cases we describe were few and simple from a technical point of view, we cannot infer that the methodology we present offers benefits over the standard video system. Nevertheless, we can say that the surgeons who participated in this study found it much easier and more intuitive to navigate within the ventricles by using this method, even though these properties are difficult to describe quantitatively in this paper. Further studies on this method should include more cases and more complex intraventricular surgeries to adequately explore the advantages of this method.

\section{Vascular Neurosurgery}

Neuroendoscope-assisted microsurgery of aneurysms is a routine practice in many centers; however, only a few case series have been published that involve investigation of the value of this method in neurovascular operations. $6,26,29,30,33$ In general, the chief surgeon performs the endoscopic procedure under microscopic guidance to avoid any unwanted damage to surrounding structures while the assistant surgeon views the endoscopy monitor. ${ }^{33}$ To resolve this limitation, some companies offer a picture-in-picture mode for their microscopes. ${ }^{14}$ Other authors prefer that the endoscopy be monitored by the assistant, and after the procedure is completed, the chief surgeon reviews the video if needed. Our experience with the smartphone was that the ease of navigation in the surgical field improved the awareness of the surgeon, thus making it less likely for the surgeon to cause injury to important structures such as vessels and nerves. Since the screen is directly affixed to the endoscope, the surgeon's vision remains focused on the surgical field, and there is no loss of spatial recognition. After the initial dissection, the chief surgeon is able to conduct the endoscopic procedure without microscopic assistance and confidently confirm the absence of any adjacent aneurysms or arteries.

\section{Emergency Neurosurgery \\ Contusional and Spontaneous Hematomas}

Recent reports have shown that the endoscopic evacuation of intracerebral hematomas is safe and effective and may have certain advantages over traditional craniotomy. ${ }^{3,24}$ The use of the smartphone as an intraoperative visualization display made the procedure more dynamic and intuitive for the neurosurgeon. Moreover, we observed that for less experienced surgeons in endoscope-assisted neurosurgery, such as the residents at our institute, the smartphone greatly reduced the learning curve. The results in our series of 12 patients indicate that early endoscopeassisted evacuation of a contusional or spontaneous hematoma is safe and effective. The rebleeding, morbidity, and mortality rates were low compared to rates reported in the literature. 9

\section{Acute Subdural Hematomas}

Endoscope-assisted burr hole evacuation of subdural collections has previously been performed in the settings of chronic and subacute $\mathrm{SDH},{ }^{8,21,23}$ subdural hygroma, ${ }^{22}$ and subdural empyemas..$^{15}$ Mobbs and Khong ${ }^{23}$ and Codd et al. ${ }^{4}$ demonstrated a similar 2-burr-hole approach to treat these subdural collections. However, it is important to distinguish an acute SDH from its chronic liquefied counter- 
parts. The hematoma itself is rubbery and adherent to brain parenchyma in cases of acute SDH. Therefore, an active extraction, rather than passive drainage, is mandatory in such cases. The use of the smartphone-endoscope set made this procedure much easier and dynamic. As the surgeon's focus remains on the surgical field, the handling of the endoscope in one hand and surgical tools in the other hand is much more intuitive and fluid.

Although Codd et al. ${ }^{4}$ were the first group to publish in a peer-reviewed journal a case in which resection of an acute SDH was performed through endoscopy, our group was the first to introduce such a method; it was presented at the Congress of Neurological Surgeons in 2012 through a poster presentation (poster no. 1292). ${ }^{20}$ The advantages of the smartphone-endoscope set lies in its ability to visualize the subdural space safely, with enhanced 3D perception of the surgical field and increased precision using the bipolar coagulation tool so the surgeon can resolve residual hematomas or active sites of bleeding. This strategy allowed the complete resection of all hematomas without any complications.

\section{Study Limitations}

We acknowledge the limitation of the preliminary results in this retrospective nonrandomized study. The patients in this study were strictly selected and represent only a fraction of all the neurosurgical patients treated in our hospital. The criteria used for selecting patients for minimally invasive procedures were based solely on the analysis and personal experience of the authors. Therefore, the good surgical outcomes and functional results may be due to patient selection.

\section{Conclusions}

The combination of smartphone technology and endoscopy may provide an alternative and relatively inexpensive method for performing minimally invasive neurosurgical procedures. This innovative use of smartphone technology can have a significant impact in underserved areas and in developing countries, where the health care infrastructure is limited. Nevertheless, further research is required to more accurately assess the actual usefulness of smartphone-endoscope integration in comparison with standard neuroendoscopic equipment in clinical scenarios.

\section{References}

1. Cappabianca P, Cavallo LM, de Divitiis E: Endoscopic endonasal transsphenoidal surgery. Neurosurgery 55:933-941, 2004

2. Cappabianca P, Cinalli G, Gangemi M, Brunori A, Cavallo LM, de Divitiis E, et al: Application of neuroendoscopy to intraventricular lesions. Neurosurgery 62 (Suppl 2):575-598, 2008

3. Cho DY, Chen CC, Chang CS, Lee WY, Tso M: Endoscopic surgery for spontaneous basal ganglia hemorrhage: comparing endoscopic surgery, stereotactic aspiration, and craniotomy in noncomatose patients. Surg Neurol 65:547-556, 2006

4. Codd PJ, Venteicher AS, Agarwalla PK, Kahle KT, Jho DH: Endoscopic burr hole evacuation of an acute subdural hematoma. J Clin Neurosci 20:1751-1753, 2013
5. Dandy WE: An operative procedure for hydrocephalus. Johns Hopkins Hosp Bull 33:189-190, 1922

6. Fries G, Perneczky A: Endoscope-assisted keyhole surgery for aneurysms of the anterior circulation and the basilar apex. Oper Tech Neurosurg 3:216-230, 2000

7. Grunert P, Gaab MR, Hellwig D, Oertel JM: German neuroendoscopy above the skull base. Neurosurg Focus 27(3):E7, 2009

8. Hellwig D, Heinze S, Riegel T, Benes L: Neuroendoscopic treatment of loculated chronic subdural hematoma. Neurosurg Clin N Am 11:525-534, 2000

9. Hemphill JC III, Greenberg SM, Anderson CS, Becker K, Bendok BR, Cushman M, et al: Guidelines for the management of spontaneous intracerebral hemorrhage: a guideline for healthcare professionals from the American Heart Association/American Stroke Association. Stroke 46:2032-2060, 2015

10. Higgins JP: Smartphone applications for patients' health and fitness. Am J Med 129:11-19, 2016

11. Ishii M, Gallia GL: Application of technology for minimally invasive neurosurgery. Neurosurg Clin N Am 21:585-594, $\mathrm{v}, 2010$

12. Jo KI, Chung SB, Jo KW, Kong DS, Seol HJ, Shin HJ: Microsurgical resection of deep-seated lesions using transparent tubular retractor: pediatric case series. Childs Nerv Syst 27:1989-1994, 2011

13. Jo KW, Shin HJ, Nam DH, Lee JI, Park K, Kim JH, et al: Efficacy of endoport-guided endoscopic resection for deepseated brain lesions. Neurosurg Rev 34:457-463, 2011

14. Kato Y, Sano H, Nagahisa S, Iwata S, Yoshida K, Yamamoto $\mathrm{K}$, et al: Endoscope-assisted microsurgery for cerebral aneurysms. Minim Invasive Neurosurg 43:91-97, 2000

15. Kirollos RW, Tyagi AK, Boles DM: Endoscopy-assisted burr hole evacuation of subdural empyema. Br J Neurosurg 10:395-397, 1996

16. Langford R: iPhone for monitoring neuromuscular function. Anaesthesia 67:552-553, 2012

17. Langley A, Mar Fan G: Comparison of the Glidescope ${ }^{\circledR}$, flexible fibreoptic intubating bronchoscope, iPhone modified bronchoscope, and the Macintosh laryngoscope in normal and difficult airways: a manikin study. BMC Anesthesiol 14:10, 2014

18. Maciunas RJ: Computer-assisted neurosurgery. Clin Neurosurg 53:267-271, 2006

19. Mandel M, Amorim R, Paiva W, Prudente M, Teixeira MJ, Andrade AF: 3D preoperative planning in the ER with Osiri $\mathrm{X}^{\circledR}$ : when there is no time for neuronavigation. Sensors (Basel) 13:6477-6491, 2013

20. Mandel M, Espirito Santo MP, Amorim RL, Andrade AF, Texeira MJ: Minimally invasive neuroendoscopic approach to acute subdural haematomas: technical note, presented at the 2012 Annual Meeting of the Congress of Neurological Surgeons, Chicago, 2012 (Poster \#1292) (http://2012.cns.org/ posterbrowser.aspx) [Accessed October 20, 2017]

21. Masopust V, Netuka D, Häckel M: Chronic subdural haematoma treatment with a rigid endoscope. Minim Invasive Neurosurg 46:374-379, 2003

22. Miyake H, Kajimoto Y, Ohta T, Kuroiwa T: Managing subdural fluid collection in infants. Childs Nerv Syst 18:500-504, 2002

23. Mobbs R, Khong P: Endoscopic-assisted evacuation of subdural collections. J Clin Neurosci 16:701-704, 2009

24. Nagasaka T, Tsugeno M, Ikeda H, Okamoto T, Inao S, Wakabayashi T: Early recovery and better evacuation rate in neuroendoscopic surgery for spontaneous intracerebral hemorrhage using a multifunctional cannula: preliminary study in comparison with craniotomy. J Stroke Cerebrovasc Dis 20:208-213, 2011

25. Nascimento CN, Amorim RL, Mandel M, do Espirito Santo 
MP, Paiva WS, Andrade AF, et al: Endoscopic-assisted removal of traumatic brain hemorrhage: case report and technical note. J Surg Case Rep 2015:rjv132, 2015

26. Profeta G, De Falco R, Ambrosio G, Profeta L: Endoscopeassisted microneurosurgery for anterior circulation aneurysms using the angle-type rigid endoscope over a 3-year period. Childs Nerv Syst 20:811-815, 2004

27. Recinos PF, Raza SM, Jallo GI, Recinos VR: Use of a minimally invasive tubular retraction system for deep-seated tumors in pediatric patients. J Neurosurg Pediatr 7:516-521, 2011

28. Sheraton TE, Wilkes AR, Hall JE: Mobile phones and the developing world. Anaesthesia 67:945-950, 2012

29. Taniguchi M, Takimoto H, Yoshimine T, Shimada N, Miyao Y, Hirata M, et al: Application of a rigid endoscope to the microsurgical management of 54 cerebral aneurysms: results in 48 patients. J Neurosurg 91:231-237, 1999

30. Wang E, Yong NP, Ng I: Endoscopic assisted microneurosurgery for cerebral aneurysms. J Clin Neurosci 10:174-176, 2003

31. Wesley KM, Fizur PJ: A review of mobile applications to help adolescent and young adult cancer patients. Adolesc Health Med Ther 6:141-148, 2015

32. Yadav YR, Yadav S, Sherekar S, Parihar V: A new minimally invasive tubular brain retractor system for surgery of deep intracerebral hematoma. Neurol India 59:74-77, 2011

33. Yamada Y, Kato Y, Ishihara K, Ito K, Kaito T, Nouri M, et al: Role of endoscopy in multi-modality monitoring during aneurysm surgery: A single center experience with 175 consecutive unruptured aneurysms. Asian J Neurosurg 10:52, 2015
34. Zaki M, Drazin D: Smartphone use in neurosurgery? APPsolutely! Surg Neurol Int 5:113, 2014

\section{Disclosures}

The authors report no conflict of interest concerning the materials or methods used in this study or the findings specified in this paper.

\section{Author Contributions}

Conception and design: Mandel, Petito, Tutihashi, Paiva, Abramovicz Mandel, Ferreira de Andrade, Figueiredo. Acquisition of data: Mandel, Petito, Tutihashi, Paiva, Figueiredo. Analysis and interpretation of data: Mandel. Drafting the article: Mandel, Abramovicz Mandel, Figueiredo. Critically revising the article: Mandel, Petito, Tutihashi, Paiva, Pinto. Reviewed submitted version of manuscript: Mandel, Tutihashi, Paiva, Abramovicz Mandel, Pinto. Approved the final version of the manuscript on behalf of all authors: Mandel. Statistical analysis: Mandel. Administrative/technical/material support: Mandel, Tutihashi, Pinto, Teixeira, Figueiredo. Study supervision: Mandel, Pinto, Ferreira de Andrade, Teixeira, Figueiredo.

\section{Correspondence}

Mauricio Mandel: University of São Paulo School of Medicine, São Paulo, Brazil. mauricio.mandel@einstein.br. 